$1=$

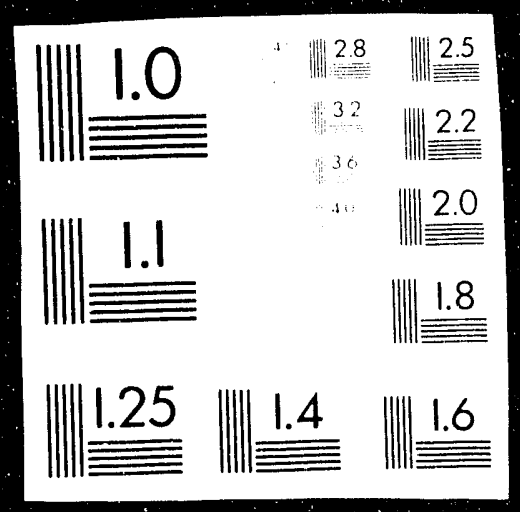

$\therefore \quad \therefore \quad \therefore$

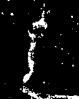




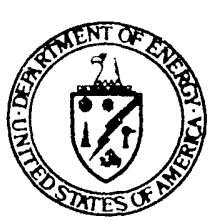

Report on

\section{Department Management of the Ross Aviation, Inc. Contract Aircraft Major Spare Parts Inventory Albuquerque, New Mexico}

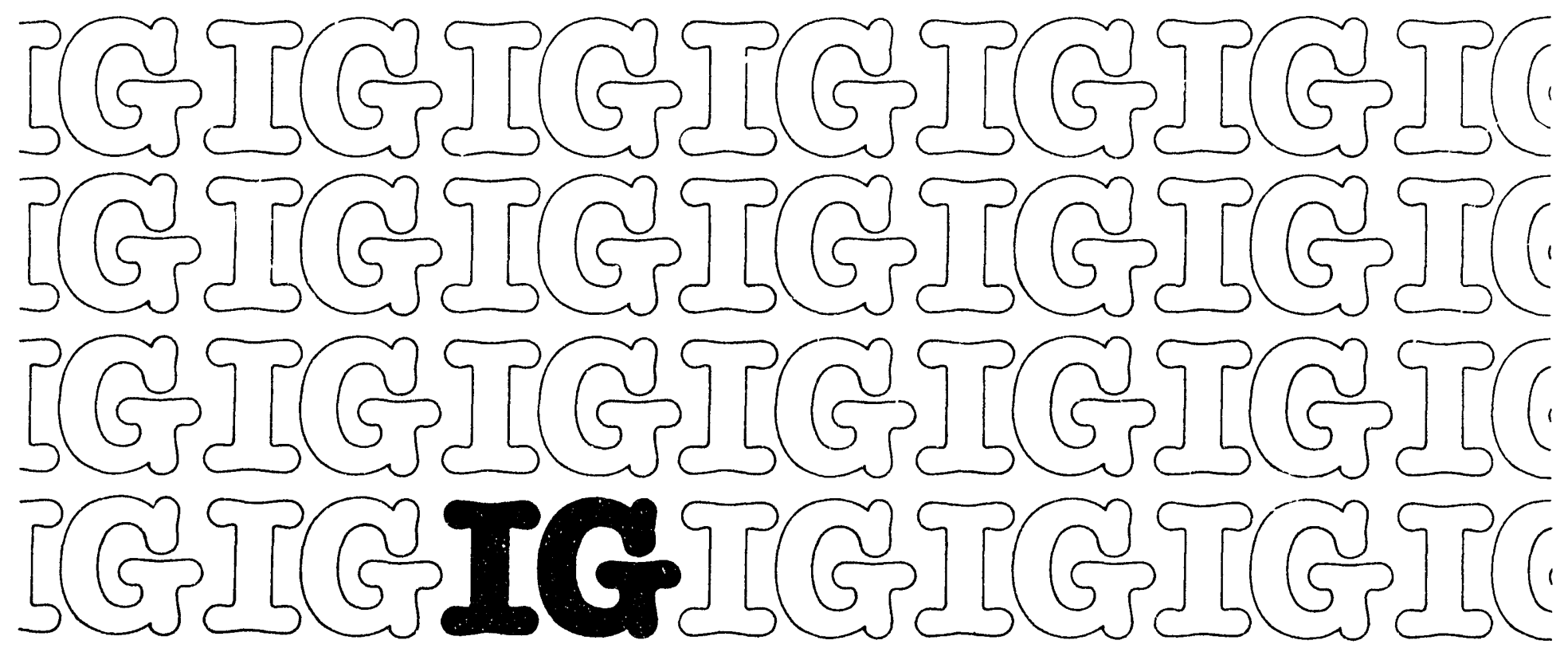


This report can be obtained from the U.S. Department of Energy

office of Scientific and Technical Information P. 0. Box 62

Oak Ridge, Tennessee 37831 


\section{DEPARTMENT MANAGEMENT OF THE ROSS AVIATION, INC. CONTRACT AIRCRAFT MAJOR SPARE PARTS INVENTORY \\ ALBUQUERQUE, NEW MEXICO}

\section{TABLE OF CONTENTS}

\section{Page}

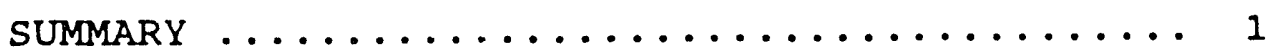

PART I $\quad$ APPROACH AND OVERVIEW $\ldots \ldots \ldots \ldots \ldots \ldots \ldots \ldots$

Purpose and objective .............. 2

scope and Methodology $\ldots \ldots \ldots \ldots \ldots \ldots \ldots \ldots \ldots$

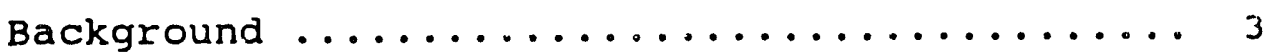

observations and conclusions ........... 4

PART II - FINDINGS AND RECOMMENDATIONS........... 5

1. Excessive Inventory at Ross.......... 5

HART III - MANAGEMENT AND AUDITOR COMMENTS .......... 8

PART IV - OTHER MATTERS .................. 10

PART $V$ - APPENDICES

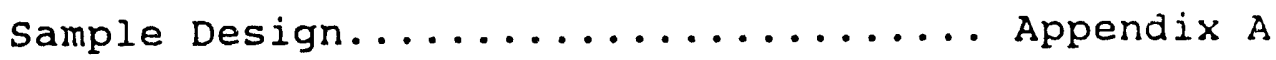




\section{U.S. DEPARTMENT OF ENERGY \\ OFFICE OF INSPECTOR GENERAL OFFICE OF AUDITS}

DEPARTMENT MANAGEMENT OF THE ROSS AVIATION, INC. CONTRACT AIRCRAFT MAJOR SPARE PARTS INVEN'TORY ALBUQUERQUE, NEW MEXICO

Audit Report Number: WR-B-91-6

July 26,1991

\section{SUMMARY}

The purpose of this audit was to determine whether the Department of Energy's (Department) management of its contract with Ross Aviation, Inc. (Ross) provided reasonable assurance that the inventory of aircraft major spare parts at Ross was economical and efficient. The audit disclosed that approximately $\$ 447,000$ (acquisition and interest carrying costs) of low-use major spare parts was excessive. Internal control deficiencies which fostered the excessive inventory included: (1) Ross had set stock levels without considering such factors as consumption or projected needs; and (2) the Department had not reviewed inventory quantities when appraising Ross' property management.

The Albuquerque operations office ( $A L$ ) agreed to take the corrective actions recommended in the report.

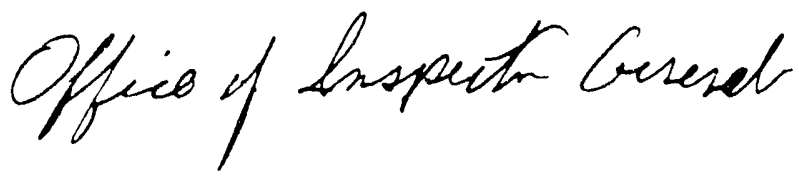


We conducted the audit to verify that the Department adequately administered Ross' inventory of aircraft spare parts. The audit objective focused on whether there was an economical and efficient inventory of major spare parts (i.e., parts with an average cost of $\$ 500$ or more).

\section{SCOPE AND METHODOLOGY}

We audited at AL Headquarters and at Ross' base operations facility from November 1989 to June 1990.

on November 2,1989 , the Department had an aircraft spare parts inventory at Ross with a total recorded cost of about $\$ 2.5$ million. We limited our review to "low-use" major spare parts, which we defined as those parts having usage of 0,1 , or 2 times between May 31, 1987 and November 2, 1989.

To accomplish the audit objective, we:

- Reviewed Department and AL regulations and policies;

- Interviewed $\mathrm{AL}$ and Ross personnel;

- Reviewed AL and Ross property management practices and procedures;

- Queried aircraft parts vendors on how quickly they coula provide certain parts to Ross;

- Reviewed Federal Aviation Administration (FAA) Regulations that allow for the publication of a Minimum Equipment List (MEL);

- Reviewed Ross' MEL "time to repair" limitations within which aircraft could be flown with certain inoperative systems; and

- Queried five other firms that operated and/or maintained aircraft to determine if there was common criteria for establishing economic inventory levels. 
On November 2, 1989, the population of low-use major spare parts consisted of 368 part numbers and 500 individual parts valued at $\$ 837,000$. We selected a sample of 55 part numbers from three strata. The 55 part numbers contained 112 parts. Stratum 1 consisted of al 25 part numbers with an extended cost of $\$ 6,000$ or more. We examined all items in stratum 1. Stratum 2 consisted of the 71 remaining part numbers which had a quantity on hand greater than one. Fifteen part numbers in stratum 2 were randomly selected for examination. Stratum 3 consisted of the 272 remaining part numbers which had a quantity on hand of one part. Fifteen part numbers in stratum 3 were randomly selected. Appendix $A$ describes the sample design.

We based our determination of reasonable inventory levels for each of the 55 part numbers on historical usage. Any inventory above the levels justified through historical usage was considered excessive inventory. The fact that four of the five aircraft firms we contacted determined spare parts inventories based on historical usage lent support to our application of this factor to Ross.

We followed generally accepted Government auditing standards for performance audits which included tests of internal controls and compliance with laws and regulations to the extent necessary to satisfy the audit objective. We assessed the significant internal controls with respect to inventory minimization. Our assessment consisted of (1) identifying the key internal control procedures that the Department and Ross had established tc minimize inventories, and (2) testing the operation of those control procedures. Because our review was limited, it would not necessarily have disclosed all internal control deficiencies that may exist. conference.

The Kirtland Area office, AL, waived the exit

\section{BACKGROUND}

Ross is an AL management and operating contractor. According to contract No. DE-AC04-89AL52318, Ross provides air transportation to the Department, the Department's contractors, and other Government elements. Ross managed, operated, and maintained eleven aircraft (three Douglas DC-9s, three DeHavilland DHC-7s, two DeHaviliand DHC-6s, two Beech BE200s, and one Cessna 305A). Although Ross provided these services, the Department, not Ross, owned or leased the facilities, aircraft, inventories, and equipment 
necessary for operations at Kirtland Air Force Base, New Mexico (base operations). Ross is responsible for ordering and maintaining custody of spare parts.

\section{OBSERVATIONS AND CONCLUSIONS}

$\cdots$ -

Ross had accumulated excessive inventory levels of low-use major spare parts. We believe this occurred because Ross had not implemented its own Department-approved inventory control procedures and had set stock levels without considering such factors as consumption or projected needs. In addition, the Department did not review inventory quantities when it appraised Ross' property management.

To correct these deficiencies, we recommended that the Department instruct Ross to implement internal controls that would provide reasonable assurance of an economical and efficient inventory, and that: AL review Ross' spare parts inventory quantities. Another recommendation was that the Department instruct Ross to return excessive parts to the vendor for cash or credit, if economically feasible.

since our field work was completed, Ross has begun to implement an automated system that, when fully operational, could foster econornic inventory levels.

This inventory finding points out internal control deficiencies which AL should consider when preparing the year-end assurance memorandum on internal controls. 


\section{FINDINGS AND RECOMMENDATIONS}

\section{Excessive Inventory at Ross}

-..

\section{FINDING}

The Department and Ross are required to maintain reasonable inventories, consistent with program needs. At Ross, approximately 59 percent of the aircraft low-use major spare parts sampled were excessive. Internal control deficiencies which fostered an excessive inventory included: (1) Ross had not implemented its Department-approved inventory control procedures -- for example, stock levels were set without considering such factors as consumption or projected needs; and (2) the Department had not reviewed inventory quantities when appraising Ross' property management. The projected cost of acquiring and carrying excessive inventory totaled about $\$ 447,000$, of which $\$ 225,000$ is considered unreasonable.

\section{RECOMMENDATIONS}

We recommend that the AL Manager:

1. Review Ross' spare parts inventory quantities as part of the normal appraisal process;

2. Require Ross to implement internal controls that will provide reasonable assurance of an economical inventory of spare parts;

3. Determine whether it is economically feasible to return excessive parts to the vendor for cash or credit; and

4. Notify Ross that in the future the Department will only reimburse for the cost of parts purchased in accordance with Department-approved inventory control procedures. 
Management agreed to implement the four recommendations. Complete management comments and auditor comments are in Part III of this report.

\section{DETAILS OF FINDING}

The Department's Property Management Regulations (DOE-PMR) require the Department to maintain reasonable inventories, consistent with program needs. The regulations specificaliy call for adequate quantity controls over inventories. Clause 66 (i) of the Ross contract requires Ross to have: a property management system that complies with the DOE-PMR.

As of November 2, 1989, approximately 59 percent of the 112 sampled aircraft low-use major spare parts at Ross were excessive, based on historical usage. The following examples are from stratum 1 .

- one part valued at $\$ 12,057$ was excessive because Ross had not issued the part since acquiring it in 1985 .

- Nine of eleven other parts (one part number) were excessive because Ross had not issued more than two parts simultaneously and had last issued one of the parts in January 1986. The nine excessive parts had a total cost of about $\$ 7,679$.

Ross had not implemented inventory control procedures which had been previously approved by the Department. For example, these procedures required Ross to base spare parts inventory levels on consumption, price, and projected needs. Although Ross established maximum stock levels and reorder points, it had no records showing these factors, or any factors, were used in setting stock levels. The approved procedures also required Ross to justify retaining items classified as low-use/no-use. Ross had no justifications. Finally, Ross procedures required biennial walk-through inspections to identify unneeued property. While Ross conducted inspections, the inspection reports showed that einphasis was placed on house-keeping and safety practices, and none of the reports iontified excessive inventory.

Ross also exceeded its own established maximum stock levels. For example, there were six parts, with a total cost of $\$ 9,973$, where the maximum established stock level was two 
parts. In another case, there were five parts with a total cost of $\$ 10,812$, where the maximum established stock level was two parts.

The DOE-PMR, as supplemented by the AL Property Management Instructions, required $A L$ to conduct birennial property management appraisals of Ross' program and system for managing Government personal property. AL conducted its appraisals less often than once every two years, and, more importantly, the 1985 appraisal that $A L$ conducted was not extensive enough to identify excess inventory. The 1985 appraisal (the most recent appraisal) did not review inventory quantities. AL's only mention of inventory quantities in the appraisal report was that reorder points and the correct amount of safety stock needed were either difficult or impossible to determine. AL recommended that Ross computerize its stores inventory but had not followed up on the effectiveness of its recommendation.

The projected cost of acquiring and carrying the excessive inventory totaled about $\$ 447,000$. The Department spent about $\$ 315,000$ acquiring the excessive inventory. Additionally, the Government has spent about $\$ 132,000$ on interest carrying cost (calculated from the date Ross received each excessive part through october 31, 1989). Appendix A, "sample Design," describes the sample projections.

In our opinion, about $\$ 225,000$ of acquisition cost is unreasonable because Ross had acquired the parts without following its Department-approved inventory control procedures. (The $\$ 225,000$ excluded the cost of parts which Ross told us it acquired because they appeared in the plane manufacturer's spare parts provisioning list. However, we excluded those parts only up to the quantity recomriended by the manufacturer). The Department's contract with Ross provides (at clause 61) that costs must be reasonable in order to be considered allowable.

Although the $\$ 315,000$ is an historical cost, the Department could save this amount or more in the future by not replacing the excessive inventory as it is used. Additionally, the Department may be able to generate cash receipts or vendor credits by returning excessive parts to the vendors. 
In response to our draft version of this report, the Area Manager, Kirtland Area office, $A L$, agreed with the recommendations and the cost savings. A summary of management's comments and our reply follow.

\section{Excessive Inventory at Ross}

\section{Management Comments}

AL stated it was conducting a property management review of Ross. The initial phase was done in June 1991, and additional reviews were scheduled for late July 1991. Future reviews will be scheduled on a biennial basis. The reviews will include aircraft spare parts inventory and control.

AL stated that it had initiated several corrective actions to insure that strong internal controls are in place at Ross. Ross' logistic management computer program is being revised to incorporate accurate cost data, historical usage factors, vendor availability information, shipping history, and mission priority requirements. Also, a 100 percent inventory of spare parts has been completed to reconcile the physical inventory to the perpetual inventory records. To insure adequate segregation of duties, the appropriate level of management reviewed and approved the physical inventory and stock record adjustments. In the future, inventories will be done annually.

To determine whether it is economically feasible to return excessive parts to the vendor, $A L$ stated it had completed an analysis of parts identified by the office of Inspector General (OIG) and other parts not included in the sample base. While selling two DHC-7 aircraft, the majority of repair parts to support flight activities were also sold to the purchaser. If it is economically advantageous, future parts that do not qualify for retention will be disposed of through the vendor. Vendors have stated that only new and unused parts would be accepted for return. The economic and logistical analysis of retaining or returning parts will address factors such as initial acquisition cost, current replacement cost, future availability and delivery, cost of money, projected utilization, and item return credits.

AL stated that a contracting officer memorandum to Ross will state the Department's position that all purchases made 
must adhere to Department-approved inventory control procedures, and that any transactions not in compliance will be considered an unallowable cost.

\section{Auditor comments} recommendations.

Ross should, in our opinion, include an economic order quantity decision model in its logistical management program. As we understand the planned operation of the program, reorder quantities are established without considering economic order quantity. The economic order quantity decision model provides information for determining the optimal purchasing policy and the management of economic inventory levels. It considers purchase-order lead time (shipping history factors) as well as carrying and ordering costs to determine reorder quantities for a given item. 


\section{OTHER MATTERS}

AL may wish to evaluate several other matters whith came to our attention during the audit. These matters are: (1) lack of travel expense account receipts; (2) weaknesses in internal control for inventory; (3) billing vehicle cost; (4) duplicate "Peculiar Parts" inventory; and (5) overstatement of mainterance contract cost accruals.

\section{Lack of Travel Exr.ense Account Receipts}

The Department's contract with Ross requires travelers to submit expense accounts supported by receipts or stubs for such items as lodging. However, Ross employees did not submit lodging recejpts. We reviewed 20 travel vouchers at Ross and found no supporting lodging receipts. Accordingly, the Department had no independent third party documentation to support the costs billed by Ross.

\section{Weaknesses in Internal control for Inventory}

The internal control structure is intended to provide reasonable assurance that financial resords are reliable. However, the following three Ross practices reduced the likelihood that its inventory records were reliable:

a) The Department's Accounting Practices and Procedures Hardbook required that the results of the physical inventory be reconciled to the perpetual invencory records. Ross did not do this.

b) For its physical inventory, Ross used a preprinted listing containing the number of parts on hand as shown in the perpetual inventory records. Knowing the number of parts shown in the records increised the possibility of an inaccurate physical inventory because the counter could simply insert the perpetual inventory quantity $a s$ the physical count.

c) Pertaining to segregation of duties, the DOE-PMR required that the review and approval of the physical inventory and stock record adjustments be done by personnel at least one supervisory level above the supervisor in charge of the inventury. Also, 41 CFR 109 stated that, preferably, personiel other than property staff or the custodian of the property should perform physical inventory. However, at Ross, personnel above the supervisor in charge of 
inventory aid not review or approve physical inventory results and adjustments. Also, the same personnel who had custody of the inventory performed the inventory.

In responding to the draft version of this reptort, A.L commented in items $a$ and $c$, above. Management comments are in Part III of the report.

\section{Billing Vehicle cost}

Under its contract with the Department, Ross is allowed to claim the incurred costs of vehicles furnished to management personnel, at the rate of $\$ 300$ per month. Ross claimec this cost until July 1990. However, December 1988 was the last time Ross management used Ross-owned vehicles. Although Ross no longer bills the Department for these costs, Ross had no basis to claim nineteen months of cost for reimbursement.

In the Department's response to the Tentative Finding and Recommendations, the Department recommended that this item be deleted from the report. It asserted that because Ross' corporate headquarters maintained one company-owned vehicle it qualified for the cost reimbursement. We do not agree. Although the vehicle was Ross-owned, i.t was not used by Ross management in the performance of Department contract work. A Ross official stated that the president of Pierce Enterprises (Ross' parent company) used the Ross-owned vehicle. Because the president of Pierce Enterprises is not an employee of Ross, Ross should not be reimbursed for the cost of this vehicle.

\section{Duplicate "Peculiar Parts" Inventory}

Under a contract with Ross, Air Canada services the DC-9 aircraft and maintains a support inventory of "peculiar spare parts". The contract creates a potential liability for the Department, for it stipulates that in the event either party terminates the contract, Ross will be liable for any accounting loss Air Canada may incur due to unsuccessful marketing attempts and/or commercial sales of the inventory.

Ross and Air Canada had 30 duplicate part numbers, indicating duplicate parts. Both entities had physical inventories for the 30 part numbers. Further, the combined physical quantities included over 80 excessive parts based on Ross' own established maximum stock levels. The Department's long-term inventory costs could possibly be reduced by 
decreasing the number of duplicate parts. Ross has authority under the Air Canada contract to control the peculiar parts inventory.

\section{Overstatement of Maintenance contract Cost Accruals}

A Department accounting directive (DOE order 2200.6 , Chapter VII) states that all liabilities are to be measured and recorded as accurately as possible. As of December 31, 1989, Ross' general ledger accounts payable balance for the DC-9 maintenance contract with Air Canade was $\$ 950,601$. However, the actual liability based on invoices from Air Canada was $\$ 208,378$. The $\$ 742,223$ difference existed for two reasons:

a) Ross made posting and accrual calculation errors which totaled about $\$ 105,082 ;$ and

b) During 1979 through 1989, Ross used the flight hour minimum in its maintenance contract to calculate the accounts payable accrual. However, Ross stated that Air Canada billed Ross for actual flight hours, which were less than the flight hour minimum. Department personnel were unsure whether Ross would ever have to pay the approximately $\$ 637,141$ difference between the recorded liability and the liability based on invoices received from Air Canada.

We believe the general ledger balance was overstated. Ross would not adjust the balance until instructions were received from $A L$.

In the response to the Tentative Finding and Recommendations, AL stated that part of the difference was due to a posting error, which had been corrected. AL also cited the fact that the Ross contract with Air Canada required Ross to pay for maintenance based on a minimum number of flight hours $(900$ flight hours per aircraft per year), and Air Canada had billed Ross only for actual flight hours, which were less than the minimum. It was necessary to accrue amounts to cover the contracted liability in the event Air Canada would bill Ross for the difference between actual flight hours and the minimum contracted hours prior to the expiration of the then existing maintenance contract. This did not occur, and the users of the Department's air services will receive credits for the unused accruals.

As of March 14, 1991, the accounts payable balance was still overstated. On April 22, 1991, an AL official stated that Ross had recently been instructed to consult wi.th Air 
Canada to determine whether it will exercise claim to the accrued monies. If Air Canada does not, Ross will either credit user accounts or reduce current users charges. AI also instructed Ross to make the appropriate corrections to the accounts payable account for the posting and/or accrual calculation errors. 


\section{SAMPLE DESIGN}

\section{Description of the Population and Sampling Unit}

The population consisted of aircraft spare parts having an average cost of $\$ 500$ or more and usage of 0,1 , or 2 times between May 31, 1987 and November 2, 1989. There were 500 such parts, having a total cost of $\$ 837,298.98$.

The sample unit was a part number. The 500 parts were contained in 368 part numbers.

\section{Audit Sampling Technique}

Nonstatistical sampling was used.

\section{Method of selecting the Sample}

We selected a sample of 55 part numbers from three strata. The 55 part numbers contained 112 parts. Stratum 1 consisted of all 25 part numbers which had an extended cost of $\$ 6,000$ or more. We examined all items in stratum 1 . stratum 2 consisted of the 71 remaining part numbers which had a quantity of parts on hand greater than one. Fifteen part numbers in stratum 2 were randomly selected for examination. stratum 3 consisted of the 272 remaining part numbers which had a quantity on hand of one part. Fifteen part numbers in stratum 3 were randomly selected for examination.

\section{Definition of an Error}

Error is the dollar amount of the excessive inventory for a sample unit.

\section{Evaluation of the Sample}

Based on our examination, we determined that 66 of the 112 parts (59 percent) were excessive.

We calculated the total error as follows. For stratum 
1, we determined actual error. For stratum 2, we projected the error by multiplying the recorded value of all part numbers in this stratum by the percentage of the stratum's sampied parts that we determined to be excessive. We used this method of projection because the dollar amount of error for the sample units (.5991 of the total value of sample units) was closer to the ratio of excess parts within the sample units (.6285 of the parts within the sample units were excessive) than to the ratio of sample units containing excessive parts $(.8667$ of the sample units contained excessive parts). For stratum 3, we projected the error amount using the same method as in stratum 2. Finally, we added the actual error for stratum 1 to the projected error for strata 2 and 3 . 

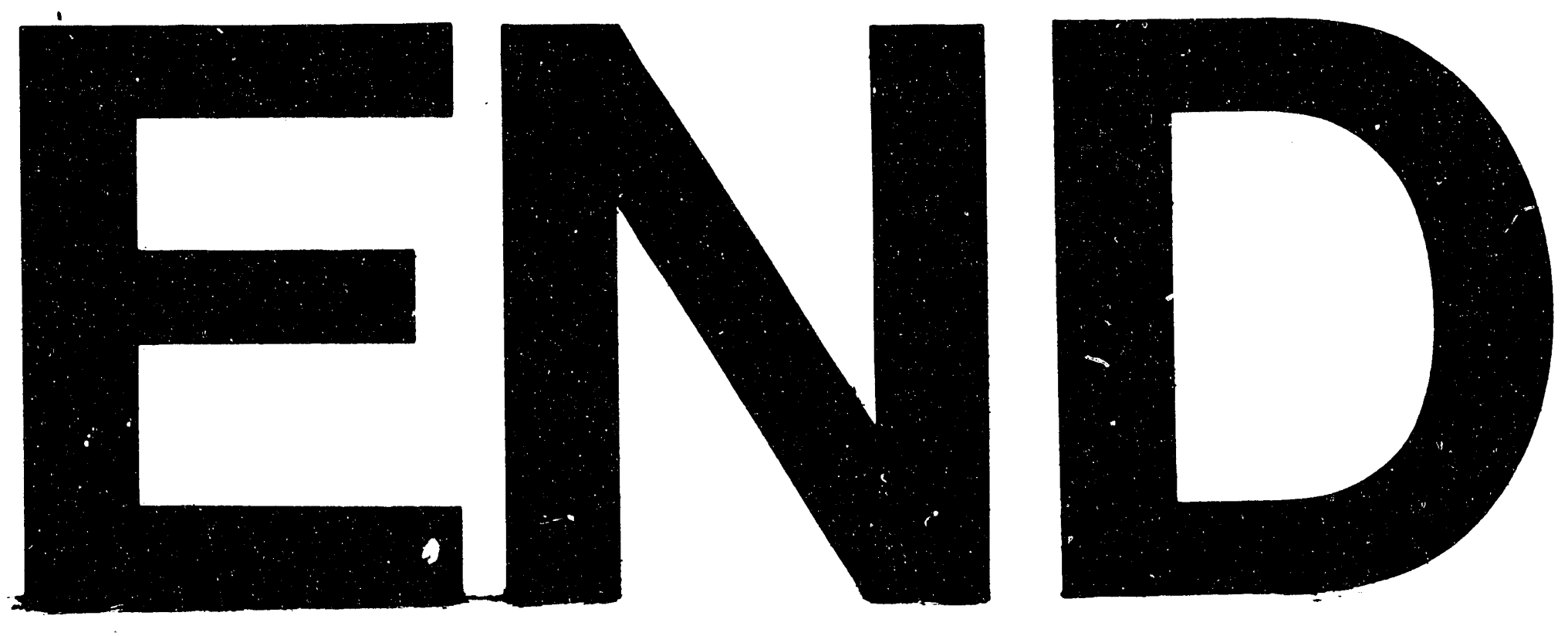

$+7$
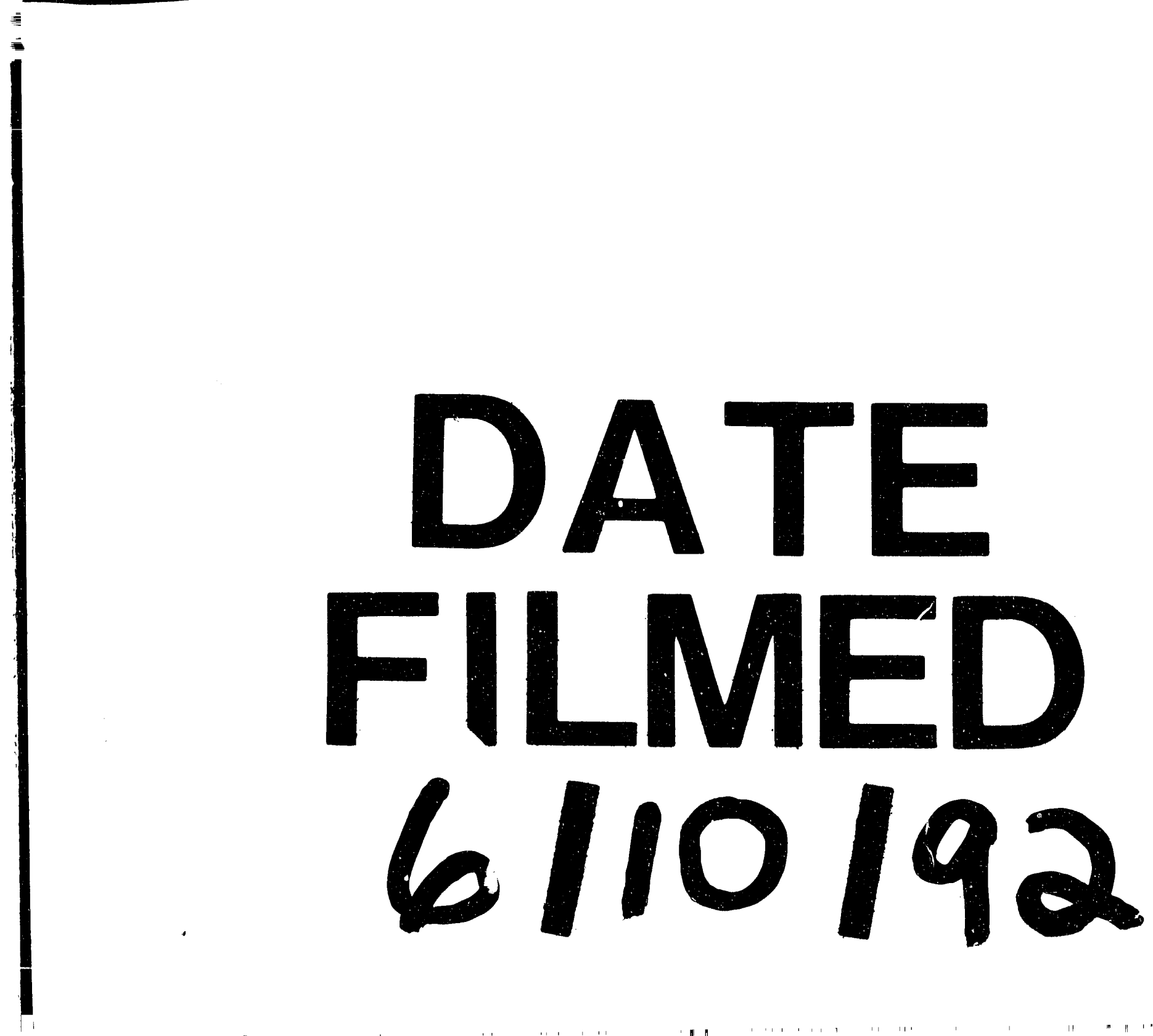
